\section{Paths to physiology}

\section{Ole H. Petersen}

Human Anatomy and Physiology.

By Eldra Pearl Solomon and P. William Davis.

Saunders: 1983. Pp.794. Hbk \$33.95, f24.95; pbk f11.95.

Animal Physiology: Mechanisms and Adaptations, 2nd Edn.

By Roger Eckert and David Randall. W.H. Freeman: 1983. Pp.830. Hbk \$32.95, £30.95; pbk £19.95.

Animal Physiology: Adaptation and Environment, 3rd Edn.

By Knut Schmidt-Nielsen.

Cambridge University Press: 1984. Pp.619. Hbk £15, \$29.95; pbk £12.95.

General and Comparative Physiology, 3rd Edn.

By William S. Hoar.

Prentice-Hall: 1983. Pp.851.

$\$ 32.95$, £31.30.

Human Physiology.

Edited by Robert F. Schmidt and Gerhard Thews.

Springer-Verlag: 1983. Pp.725. DM98, $\$ 39.20$.

PFLUGER, the founder of the oldest extant physiological journal, insisted that as the science of living matter physiology could not be divided into physiological physics and physiological chemistry. However, to a certain extent this has happened. Physiology courses now generally do not include biochemistry, the practice being reflected in most current textbooks. Nonetheless the borders between physiology and biochemistry are ill defined, particularly in areas such as membrane transport, neurobiology and endocrinology - all amongst the growth points in the life sciences.

The authors of the five basic textbooks under review follow different paths in this respect. The most elementary of the books, Human Anatomy and Physiology, includes substantial amounts of (basic) biochemistry, whereas at the other end of the spectrum Human Physiology contains virtually no biological chemistry leaving, for example, the chapter on endocrinology with bleeding wounds.

Human Anatomy and Physiology is a new textbook (as opposed to a new edition), mainly designed for introductory courses in the health sciences. It has a trendy appearance, with many coloured diagrams and various boxes with special inserts, and at the end of each chapter one finds summary, "post-test" and review questions. Each chapter is also preceded by an outline, learning objectives and key terms. The illustrations are of good quality; many are excellent. The book is comprehensive at a very basic level and could well become a popular choice for nurses as well as different categories of medical technologists. There are, however, some misleading statements and factual errors. These are particularly conspicuous in the areas of cellular physiology and should be corrected in future editions.

The two versions of Animal Physiology as well as General and Comparative Physiology are designed for science students taking physiology courses within departments of physiology or zoology. Of the three, Eckert and Randall's book, now appearing in its second edition, is by far the most impressive. It has already acquired a solid reputation which is bound to grow further since the authors do indeed, as claimed in the preface, "develop the major ideas in a simple and direct manner stressing principles and mechanisms. .." The standard of presentation is very high indeed, the figures being instructive as well as visually attractive. Each chapter ends with a summary and exercises; and in addition to a reading list, directing students to important reviews and books, there is a set of references (on the whole up-to-date) actually cited in the text. Many of the chapters are far superior to the treatment found in other textbooks, including those intended for medical students (for example, Chapter 11 on chemical messengers and regulators contains a clear description of the role of cyclic AMP and $\mathrm{Ca}^{2+}$ as intracellular messengers for the action of hormones, something sadly lacking in most other texts). I recommend this book without reservations, first of all to the physiology students it is intended for, but also to medical students as a supplement to their standard reading.

Schmidt-Nielsen's well-known Animal Physiology, now in its third edition, is a somewhat briefer account with more emphasis on adaptation and environment. The text is straightforward without any gimmicks. However chapters dealing with several important areas, for example neurophysiology, are lightweight. A particularly unfortunate figure, schematically illustrating synapses that effect electrical and chemical transmission, has the latter labelled as a "tight junction"'!

Hoar's General and Comparative Physiology, also in its third edition, is comparable in length and cost to Eckert and Randall's Animal Physiology but cannot stand up to the competition. The layout, quality of figures, clarity and depth of treatment as well as the references are all inferior. It is nevertheless a solid book, containing good chapters on homeostatic mechanisms and endocrine regulation of reproduction.

Human Physiology is a good English translation of Schmidt and Thews's textbook which has appeared in numerous German editions. Although there is already an impressive number of English and American textbooks for the large medical market, this one could eventually become a best-seller. The presentation is excellent. The figures are of a uniformly high standard (mostly they are schematic, in black, grey, white and red, but with original records included as required), genuinely help understanding and are well integrated with the text. The chapters on neuroscience and the accounts of the cardiovascular and respiratory systems are in my opinion superior to those in comparable medical physiology textbooks. This will be good enough for some potential purchasers and Human Physiology will be seen by many dental and medical students as a good first choice of textbook on the subject.

It is therefore annoying that it is not possible to recommend the book without reservations. The balance is not right. Almost exactly half of the book ( 328 pages) is taken up by the nervous system. As a consequence, other areas - some of them of immediate importance in the study of internal medicine - are unacceptably neglected. Two areas are very badly hit: the gastrointestinal tract (22 pages) and the endocrine system (29 pages). The chapter on the function of the gastrointestinal canal conveys the completely wrong impression that this field is a backwater of physiology on which new technologies, for example in cellular physiology, have made little impression. The references listed at the end of the chapter do not help very much as they are rather dated. The endocrine chapter, however, is the worst. Incredibly, mechanisms of action receive only about 200 words, with the unsatisfactory excuse that this is an area discussed in biochemical and specialized texts. This certainly is not in line with the course requirements of most medical-school physiology departments in the United States and Britain. The sections on special endocrinology are also too brief and are unsatisfactory as seen, for example, in the superficial treatment of the pancreatic hormones and the control of blood glucose. These deficiences must be rectified if the book is to achieve the success it otherwise so richly deserves.

Authors of physiology textbooks are not known for taking up new ideas quickly. It is nevertheless sad that although the books reviewed all describe in some detail the electrical membrane characteristics of nerve and muscle cells, proclaiming this area as one in which some of the triumphs in physiology have been won, none of the authors seem to have appreciated the impact that patch-clamp single-channel current recordings could have at the level of undergraduate teaching. It has been my experience that the molecular approach to membrane physiology, with an emphasis on specific ion pathways studied at the level of single-channels, makes it much easier for the student to understand basic electrophysiological concepts. Do physiology textbook authors have to wait until Neher and Sakmann have been awarded the Nobel Prize before they take into account this revolution in neurobiology?

Ole H. Petersen is George Holt Professor of Physiology at the University of Liverpool. 